OPEN ACCESS

Edited and reviewed by: Jon Chorover,

University of Arizona, United States

${ }^{*}$ Correspondence:

Carl I. Steefel cisteefe/@lbl.gov

Specialty section:

This article was submitted to Water and Critical Zone, a section of the journal Frontiers in Water

Received: 01 December 2021 Accepted: 06 December 2021 Published: 06 January 2022

Citation:

Steefel Cl, Navarre-Sitchler A and Sullivan PL (2022) Editorial: Chemical Export to River Systems From the Critical Zone. Front. Water 3:826731.

doi: 10.3389/frwa.2021.826731

\section{Editorial: Chemical Export to River Systems From the Critical Zone}

\author{
Carl I. Steefel ${ }^{1 *}$, Alexis Navarre-Sitchler ${ }^{2}$ and Pamela L. Sullivan ${ }^{3}$ \\ ${ }^{1}$ Energy Geosciences Division, Lawrence Berkeley National Laboratory, Berkeley, CA, United States, ${ }^{2}$ Department of \\ Geology and Geological Engineering, Colorado School of Mines, Golden, CO, United States, ${ }^{3}$ College of Earth, Ocean, and \\ Atmospheric Sciences, Oregon State University, Corvallis, OR, United States
}

Keywords: chemical export, Critical Zone, weathering, rivers, watersheds

Editorial on the Research Topic

Chemical Export to River Systems From the Critical Zone

There is a growing recognition that the Critical Zone (CZ), extending from the vegetation canopy into soils and deeper permeable bedrock, is an important source of chemical constituents that make their way into river systems. In this regard, the Critical Zone exercises a primary control on water quality. Chemical fluxes to river systems may originate in soils, where various plant and carbonmediated physical and biogeochemical processes are expected to dominate, or from weathering of bedrock (saprolite) in the shallow Critical Zone where rock forming minerals dissolve, to the deeper Critical Zone where flow paths with long travel times may produce more concentrated solutions high in metals, anions, and cations. All of these compartments within the Critical Zone export solutes to rivers within watersheds, and their relative contribution is expected to change due to seasonal and longer-term transients.

The export of chemical constituents to a river system requires hydrological gradients, which typically follow muted contours of the land surface. Relatively flat-lying terrain bordering a river system is expected to export water and solutes from shallow flow paths, while steeper terrain may result in export from both shallow and deeper flow paths. The topic of chemical export to river systems has created renewed interest into hillslope models, which historically have been primarily hydrological, but are now beginning to include chemical processes as well. Characterization of the hillslope environment in terms of geochemistry, plant distribution, and hydrological flow is now considered an important part of the study of chemical weathering, which previously focused primarily on purely vertical profiles (1D downward flow). Studies by Lebedeva and Brantley (2020) and Wan et al. (2021) provided the basis for a new conceptual model that places the chemical weathering front in the hillslope at the position of the water table, which moves up and down by about $2 \mathrm{~m}$ over the course of the year. In this case, the primary mineralogy of the shale undergoing weathering includes pyrite, which reacts with oxygen in the soil porewater to form sulfate and acidity that contribute further to the weathering process. Because oxygen diffuses 3-4 orders of magnitude faster in the unsaturated zone where a gas phase is present than it does in fully saturated media, the position of the water table becomes an important constraint on the location of any redox fronts that develop, if such exist. The rise and fall of the water table over the course of a year provides an additional transport mechanism for oxygen beyond pure diffusion (Yabusaki et al., 2017; Dwivedi et al., 2018; Lebedeva and Brantley, 2020; Wan et al., 2021).

\section{MODELING CHEMICAL EXPORT FROM CRITICAL ZONE}

Most of the interest in modeling of chemical weathering has come from the role that it can play in the long-term regulation of atmospheric $\mathrm{CO}_{2}$. This important effect has been known to 
geochemists for many years of course, but more recently has been "rediscovered" by those interested in engineering $\mathrm{CO}_{2}$ uptake by weathering processes (so-called "negative emissions"). The earliest models for chemical weathering were one-dimensional (Lichtner and Waber, 1992; Soler and Lasaga, 1998), and perhaps because they appeared before the community was able to assimilate such modeling approaches, they quickly fell into the dustbins of Google Scholar. A more complete modeling study was built on a comprehensive weathering dataset from White and co-workers, and demonstrated that both present-day aqueous geochemical porewater and mineralogical profiles could be captured with a single model that required little adjustment of laboratory rate constants (Maher et al., 2009). At even smaller scales, Navarre-Sitchler et al. (2011) considered diffusioncontrolled reactions in weathering basaltic andesite and showed that rates of weathering rind propagation could be captured with a single model that included porosity-permeability feedbacks between weathering reactions and diffusivity. For recent 2D hillslope modeling studies (see Dontsova et al., 2009; Gu et al., 2020; Lebedeva and Brantley, 2020; Xiao et al., 2021).

Flow and reactive transport processes not only govern the formation and evolution of reaction zones (or weathering fronts) in the Critical Zone, they also control the chemical export to the river system. One can speak of concentration-discharge or C-Q relationships within the hillslope environment itself, but these represent exports to the larger riverine system where C-Q relationships record the aggregated response of the watershed. In the study by Ackerer et al. (this volume), geomorphologic analysis, C-Q relations and reactive-transport modeling are used together with a rich dataset from an elevation gradient of eight watersheds in the Southern Sierra Nevada, California. The authors found that the $\mathrm{CZ}$ structure exerts a strong control on the $\mathrm{C}-\mathrm{Q}$ relations, and on the hydrogeochemical behavior of headwater watersheds. Watersheds with thin regolith, a large stream network, and limited water storage have fast mean transit times along subsurface flow lines, and show limited seasonal variability in ionic concentrations in streamflow as a result (i.e., they demonstrate chemostatic behavior). In contrast, watersheds with thicker regolith, a smaller stream network, and more water storage have longer transit times along subsurface flow lines, and exhibit greater chemical variability (i.e., they show chemodynamic behavior). Note that in this pioneering study, the stream chemistry and its variability were controlled by lateral flow within the regolith, and no mixing with deep groundwater was needed to explain the observed chemical variability.

\section{SOIL MOISTURE AND HYDROLOGIC CONNECTIVITY}

In a contribution from Hermes et al. (this volume), the authors determine how the interacting drivers of precipitation and physical controls of the critical zone $(\mathrm{CZ})$ dictate the spatial pattern and time evolution of soil water storage. The authors developed an analytical framework that combines intensive hydrologic measurements and extensive remotelysensed observations with statistical modeling to identify areas with similar temporal trends in soil water storage focusing on $0.26 \mathrm{~km}^{2}$ alpine catchment in the Colorado Rocky Mountains, U.S.A. Repeat measurements of soil moisture were used to drive an unsupervised clustering algorithm, which identified six unique groups of locations ranging from predominantly dry to persistently very wet, within the catchment. Following this unsupervised learning exercise, the authors used a supervised machine learning random forest algorithm to map each of the six hydrologic groups across the catchment based on distributed $\mathrm{CZ}$ properties and evaluated their aggregate relationships at the catchment scale. Their analysis indicated that $\sim 40-50 \%$ of the catchment is hydrologically connected to the stream channel. Their approach identifies a useful approach to categorizing patches within the landscape with similar hydrologic function, as well as the connectivity of these zones to the stream network.

\section{EXPORT OF CARBON}

Streams and rivers integrate and transport particulate organic carbon from a variety of aquatic and terrestrial sources. In the study by Blair et al. (this volume), a 3rd-4th order agricultural stream network was sampled at a nested series of stations through storm events to determine how suspended particulate organic carbon (POC) changes over time and with distance along the stream network. Carbon and nitrogen stable isotope ratios were used to identify changes in POC. A temporal sequence of inputs was identified: in-channel algal production prior to heavy precipitation, row crop surface soils mobilized during peak precipitation, and material associated with the peak hydrograph that is hypothesized to be an integrated product from upstream. Tile drains delivered relatively $13 \mathrm{C}$ - and $15 \mathrm{~N}$-depleted particulate organic carbon that represent a small contribution to the total POC inventory in the return to baseflow. The storm POC signal evolved with passage downstream, the principal transformation being the diminution of the early flush surface soil peak in response to a loss of connectivity between the hillslope and channel. Bank erosion is hypothesized to become increasingly important as the signal propagates downstream. The evolution of the POC signal along the length of the river system has implications for C-budgets associated with soil erosion, and ultimately for the interpretation of the organic geochemical sedimentary record.

A second study by Adler et al. (this volume) aims to understand and predict catchment responses of carbon to regional disturbances, an objective that is difficult because catchments represent spatially heterogeneous systems. The authors used a novel dataset that integrates regional and catchment-scale atmospheric deposition data, catchment characteristics, and co-located stream Q and stream chemistry data through a pattern-to-process approach. This approach is used to explore regional patterns of reduced acid deposition, catchment characteristics, and stream DOC response and specific soil processes at select locations. For pattern investigation, they quantified long-term trends of flow-adjusted DOC concentrations in stream water, along with wet deposition trends in sulfate and then compare trend results to catchment 
attributes. Their investigation of climatic, topographic and hydrologic catchment attributes vs. directionality of DOC trends suggests soil depth and catchment connectivity as possible modulating factors for DOC concentrations. Results from this work illustrate the value of an iterative process and pattern approach to understand catchment-scale response to regional disturbance.

\section{TRACE ELEMENT AND ISOTOPE EXPORT}

The Critical Zone is an important source of trace elements to headwater streams during the snowmelt runoff period, yet the mechanisms of trace element export are poorly known. To evaluate changes in water chemistry in response to snowmelt, Checketts et al. (this volume) measured trace element and major ion concentrations at three sites in the upper Provo River in northern Utah, USA over a 5-year period spanning years with below- and above-average discharge. Concentrations of specific trace metals $(\mathrm{Be}, \mathrm{Al}, \mathrm{Cu}$, and $\mathrm{Pb}$ ) and rare earth elements (represented by La and Y) increased during snowmelt runoff each year at all three sites, with decreasing concentrations from upstream to downstream. In contrast, major ion concentrations, including $\mathrm{Ca}^{2+}$ and $\mathrm{SO}_{4}^{2-}$, remained relatively constant at the upper site and were diluted during snowmelt at the lower sites. The snowmelt runoff period accounted for $>84 \%$ of the annual trace element loading, with most trace element inputs occurring above the upper sampling site. Trace element concentrations were relatively low in snowpack but elevated in ephemeral streams and soil water, suggesting that flushing of shallow soils by snowmelt causes increased trace element concentrations with positive $\mathrm{C}-\mathrm{Q}$ relationships in the upper part of the river. Their results demonstrate that soil water flushing in the Critical Zone at the headwaters of mountain streams is an important control on downstream water chemistry.

In another study, Garcia et al. (this volume) found that in semi-arid to arid regions, both anthropogenic sources (urban and agriculture) and deeper Critical Zone (groundwater) may play an important role in controlling chemical exports to rivers. The authors combined two anthropogenic isotope tracers: uranium isotope ratios $\left({ }^{234} \mathrm{U} /{ }^{238} \mathrm{U}\right)$ and boron isotope ratios $\left(\delta^{11} \mathrm{~B}\right)$, with the ${ }^{87} \mathrm{Sr} /{ }^{86} \mathrm{Sr}$ ratios to identify and quantify multiple solute (salinity) sources in the Rio Grande river in southern New Mexico and western Texas.

In another study, Moquet et al. (this volume) investigated cratonic environments that are characterized by strongly variable weathering rates. They studied the weathering rates in two intertropical river basins from the Atlantic Central Africa: the Ogooué and Mbei River basins, Gabon. Based on the determination of the major element sources they estimated that the Ogooue and Mbei rivers total dissolved solids (TDS) derive primarily from silicate chemical weathering. Chemical weathering rates span the entire range of chemical weathering intensities hitherto recorded in worldwide cratonic environments. In the OgoouéMbei systems, three regions can be distinguished: (i) the Eastern sub-basins underlain by quartz-rich sandstones exhibit the lowest weathering rates, (ii) the Northern sub-basins and the Mbei sub-basins, which drain the southern edge of the tectonically quiescent South Cameroon Plateau, show intermediate rates, and (iii) the Southern sub-basins characterized by steeper slopes record the highest weathering rates. In region (ii), higher DOC concentrations are associated with enrichment of elements, suggesting enhanced transport of these elements in the colloidal phase. The study points out that erosion of lateritic covers in cratonic areas can significantly enhance chemical weathering rates by bringing fresh minerals in contact with meteoric water.

\section{METALS EXPORT}

High concentrations of trace metal(loid)s exported from abandoned mine wastes and acid- rock drainage may pose a risk to the health of aquatic ecosystems. In a study by Hoagland et al. (this volume), the authors aim to determine if and when the hyporheic zone mediates metal(loid) export by investigating the relationship between streamflow, groundwaterstream connectivity, and subsurface metal(loid) concentrations in two $\sim 1 \mathrm{~km}$ stream reaches within the Bonita Peak Mining District near Silverton, Colorado, USA. The hyporheic zones of reaches in two streams-Mineral Creek and Cement Creekwere characterized using a combination of salt-tracer injection tests, transient-storage modeling, and geochemical sampling of the shallow streambed. Based on these data, the authors present two conceptual models for subsurface metal(loid) behavior in the hyporheic zones, including (1) well-connected systems characterized by strong hyporheic mixing of infiltrating stream water and upwelling groundwater and (2) poorly connected systems delineated by physical barriers that limit hyporheic mixing. Comparison of the conceptual models to stream concentration-discharge relationships indicated a clear link between geochemical processes occurring within the hyporheic zone of the well-connected system and export of particulate $\mathrm{Al}$, $\mathrm{Cu}, \mathrm{Fe}$, and $\mathrm{Mn}$, while the poorly connected system did not have a significant influence on metal concentration-discharge trends. Mineral Creek was an example of a hyporheic system that serves as a natural dissolved metal(loid) sink, while a poorly connected system such as Cement Creek may benefit more from subsurface remediation than surface-water treatment to mitigate metal export.

Dong et al. (this volume) further investigate the role of hyporheic zones as critical ecological links between terrestrial and aquatic systems where redox-sensitive metals (notably Fe and $\mathrm{Mn}$ ) significantly impact nutrient cycling and water quality. The authors conducted batch incubation experiments and analyzed Fe K-edge extended X-ray absorption fine structure (EXAFS) spectroscopy data using sediment samples from a hyporheic zone of the East River floodplain in Colorado to understand the production, release and speciation of $\mathrm{Fe}(\mathrm{II})$ and $\mathrm{Mn}$ (II) in groundwater. The sediments with higher Fe(II) production rates did not necessarily result in higher export of dissolved $\mathrm{Fe}(\mathrm{II})$, since $\geq 97 \% \mathrm{Fe}(\mathrm{II})$ is accumulated in solid phase. They found that most of the Fe(II) exists as siderite (FeCO3), Fe(II)natural organic matter (NOM) complexes, and ferro-smectite. 
In contrast, dissolved $\mathrm{Mn}$ (II) increases slowly and linearly in batch experiments, and an equilibrium concentration was not reached during the incubation period. This work reveals that siderite and dissolved NOM are the controlling phases in release and speciation of dissolved Fe(II), and the finding is expected to be applicable in many hyporheic zones and subsurface environments with similar geochemical conditions.

\section{EXPORT IN KARST ENVIRONMENTS}

In a study by Qin et al. (this volume) designed to explore hydrogeochemical sources, dynamics and their responses to rainstorms, rainwater, throughfall, hillslope runoff, surface water and groundwater were sampled during rainstorms at a karst Critical Zone Observatory $(\mathrm{CZO})$ in southwest China. Results showed that the total dissolved solids (TDS) concentration in throughfall increased by about $30 \%$ relative to rainwater, but both throughfall and rainwater contributed little to TDS in surface water and groundwater compared with terrestrial sources. Hydrochemistry in surface water and groundwater were diluted by rainstorms, but typically displayed chemostatic responses. $\mathrm{Ca}^{2+}$ and $\mathrm{Mg}^{2+}$ dynamics were regulated primarily by carbonate and gypsum weathering along with sulfateinduced dedolomitization. The chemostatic behaviors of $\mathrm{NO}_{3}^{-}$, $\mathrm{Cl}^{-}$, and $\mathrm{K}^{+}$were related to agricultural activities. The heterogeneous permeability of epikarst (the skin of the karst) can affect the mixture of groundwater from different sources and flowing pathways, enabling hydrochemistry under different

\section{REFERENCES}

Dontsova, K., Steefel, C. I., Desilets, S., Thompson, A., and Chorover, J. (2009). Solid phase evolution in the Biosphere 2 hillslope experiment as predicted by modeling of hydrologic and geochemical fluxes. Hydrol. Earth Syst. Sci. 13, 2273-2286. doi: 10.5194/hess-13-2273-2009

Dwivedi, D., Steefel, C. I., Arora, B., Newcomer, M., Moulton, J. D., Dafflon, B., et al. (2018). Geochemical exports to river from the intrameander hyporheic zone under transient hydrologic conditions: East River Mountainous Watershed, Colorado. Water Res. Res. 54, 8456-8477. doi: 10.1029/2018WR023377

Gu, X., Rempe, D. M., Dietrich, W. E., West, A. J., Lin, T.-C., Jin, L., et al. (2020). Chemical reactions, porosity, and microfracturing in shale during weathering: The effect of erosion rate. Geochim. Cosmochim. Acta 269, 63-100. doi: 10.1016/j.gca.2019.09.044

Lebedeva, M. I., and Brantley, S. L. (2020). Relating the depth of the water table to the depth of weathering. Earth Surface Process. Landforms 45, 2167-2178. doi: $10.1002 /$ esp. 4873

Lichtner, P. C., and Waber, N. (1992). Redox front geochemistry and weathering: theory with application to the Osamu Utsumi uranium mine, Pocos de Caldas, Brazil. J. Geochem. Explorat. 45, 521-564. doi: 10.1016/0375-6742(92)90138-X

Maher, K., Steefel, C. I., White, A. F., and Stonestrom, D. A. (2009). The role of reaction affinity and secondary minerals in regulating chemical weathering rates at the Santa Cruz Soil Chronosequence, California. Geochim. Cosmochim. Acta 73, 2804-2831. doi: 10.1016/j.gca.2009.01.030

Navarre-Sitchler, A., Steefel, C. I., Sak, P. B., and Brantley, S. L. (2011). A reactive transport model for weathering rind formation on basalt. Geochim. Cosmochim. Acta 75, 7644-7667. doi: 10.1016/j.gca.2011.09.033

Soler, J. M., and Lasaga, A. C. (1998). An advection-dispersionreaction model of bauxite formation. J. Hydrol. 209, 311-330. doi: 10.1016/S0022-1694(98)00090-0 hydrogeological conditions to display quite different responses to rainstorms.

\section{CONCLUDING REMARKS}

The contributions in this special issue point to the emergence of a new field in coupled chemical and hydrological processes of importance to the Critical Zone and to the chemistry of river systems. Chemical weathering results in release of elements that can then be transported via flow to nearby river systems. The hillslope environment is critical here, since the topography provides the basis for the hydrological gradients driving flow to the riverine system. Ultimately, the chemistry of river systems can only be understood by tracing chemical and flow processes back to their origin in the watershed.

\section{AUTHOR CONTRIBUTIONS}

All authors listed have made a substantial, direct, and intellectual contribution to the work and approved it for publication.

\section{FUNDING}

CS was supported by the Watershed Function Science Focus Area and ExaSheds projects at Lawrence Berkeley National Laboratory funded by the U.S. Department of Energy, Office of Science, and Biological and Environmental Research under Contract No. DEAC02-05CH11231. AN-S was supported in part by the National Science Foundation under Award 436 No. EAR-15540.

Wan, J., Tokunaga, T. K., Brown, W., Newman, A. W., Dong, W., Bill, M., et al. (2021). Bedrock weathering contributes to subsurface reactive nitrogen and nitrous oxide emissions. Nat. Geosci. 14, 217-224. doi: 10.1038/s41561-021-00717-0

Xiao, D., Brantley, S. L., and Li, L. (2021). Vertical connectivity regulates water transit time and chemical weathering at the hillslope scale. Water Res. Res. 57:e2020WR029207. doi: 10.1029/2020WR02 9207

Yabusaki, S. B., Wilkins, M. J., Fang, Y., Williams, K. H., Arora, B., Bargar, J., et al. (2017). Water table dynamics and biogeochemical cycling in a shallow, variably-saturated floodplain. Environ. Sci. Technol. 51, 3307-3317. doi: 10.1021/acs.est.6b04873

Conflict of Interest: The authors declare that the research was conducted in the absence of any commercial or financial relationships that could be construed as a potential conflict of interest.

Publisher's Note: All claims expressed in this article are solely those of the authors and do not necessarily represent those of their affiliated organizations, or those of the publisher, the editors and the reviewers. Any product that may be evaluated in this article, or claim that may be made by its manufacturer, is not guaranteed or endorsed by the publisher.

Copyright (c) 2022 Steefel, Navarre-Sitchler and Sullivan. This is an open-access article distributed under the terms of the Creative Commons Attribution License (CC $B Y)$. The use, distribution or reproduction in other forums is permitted, provided the original author(s) and the copyright owner(s) are credited and that the original publication in this journal is cited, in accordance with accepted academic practice. No use, distribution or reproduction is permitted which does not comply with these terms. 